\title{
Advancing interdisciplinary research: Insights from the JIBS special issue
}

Joseph LC Cheng ${ }^{1}$,

Julian Birkinshaw ${ }^{2}$,

Donald R Lessard ${ }^{3}$ and David C Thomas ${ }^{1}$

${ }^{1}$ Australian School of Business, University of New South Wales, Sydney, Australia; ${ }^{2}$ London Business School, London, UK; ${ }^{3}$ MIT Sloan School of Management, Cambridge, USA

\section{Correspondence:}

JLC Cheng, Australian School of Business, University of New South Wales, Sydney, NSW 2052, Australia.

Tel: +61 9385 8806;

email: joecheng@unsw.edu.au

\begin{abstract}
Twenty-five years ago, Dunning articulated a vision for greater interdisciplinary grounding in international business (IB) research. Motivated by his foresight, this special issue aims to encourage research that explicitly combines ideas from different disciplines, with a view to creating new integrative theories with greater explanatory power than those based on a single discipline. Five articles selected from a pool of 60 submissions are presented in the special issue, each with its own distinctive interdisciplinary contribution to expanding our knowledge about an important IB phenomenon. In editing the special issue, the editors developed a new understanding of the opportunities and challenges in conducting interdisciplinary research. These insights are reported in the current editorial essay. We conclude by discussing four approaches to interdisciplinary inquiry observed across the five accepted papers: (1) addressing a new phenomenon, (2) asking a fresh question, (3) finding a better answer and (4) contributing to a base discipline.

Journal of International Business Studies (2014) 45, 643-648. doi: I0. I057/jibs.20I4.34
\end{abstract}

$\overline{\text { Keywords: interdisciplinary research; multilevel analysis; new theory development; new }}$ research directions; integrative theorizing; bridging between disciplines

\section{INTRODUCTION}

As an academic field of study, international business (IB) seeks to develop our understanding of the nature, antecedents and consequences of business activities that cross national borders. Many of these activities can only be understood properly through multiple lenses and levels of observation, and they are often embedded in multifaceted contexts with economic, cultural, legal and political elements (Birkinshaw, Brannen, \& Tung, 2011; Cheng, Henisz, Roth, \& Swaminathan, 2009).

To adequately capture this inherent complexity, there have been repeated calls for IB scholars to conduct research that combines ideas and methods from two or more disciplines (e.g., Buckley \& Lessard, 2005; Daniels, 1991; Dunning, 1989). It goes without saying that IB encourages multidisciplinary research, which involves bringing together scholars from different base disciplines to study phenomena of common interest, but from their own perspectives. However, this sometimes devolves into a set of parallel discussions of the international dimensions of various functions, rather than a truly generative cross-disciplinary conversation. The bar for defining research as interdisciplinary is significantly higher: it requires ideas from different disciplines to be combined, and it develops integrative 
theories that have greater explanatory power than those based on a single discipline (Cantwell \& Brannen, 2011; Cheng, Guo, \& Skousen, 2011).

Despite the clear need and potential benefits of interdisciplinary research, IB scholars have been slow in responding to these calls. When the IB field first emerged some 50 years ago, its founding members were mostly economists who applied their disciplinary knowledge to study international trade and investment (Rugman, Verbeke, \& Nguyen, 2011). This emphasis on economics-based theories has lessened over the years, with increasing numbers of IB researchers drawing on theories and using tools from sociology, psychology and political science to understand their phenomena of interest. But it is still the case that most IB scholars have an academic background in a single social science discipline and are accustomed to developing and defending their arguments to peers from the same background. They also may not have the skills required for interdisciplinary research, and may work across disciplinary boundaries without sharply defining the bases from which they are working. Alternatively, reviewers, also typically grounded in a single discipline, may not appreciate the interdisciplinary nature of the work. As a result, journals such as JIBS continue to feature studies that are primarily grounded in a single discipline.

Of course, interdisciplinary research is not a panacea, and we would not want to suggest that all IB research should be interdisciplinary. The fact that a phenomenon is complex does not by itself justify an interdisciplinary approach. When a phenomenon is very complex, it is sometimes better to first chip away at it within well-understood paradigms and methodologies. Being eclectic by itself is not a virtue; it is most desirable when framing a phenomenon with complementary perspectives yields important insights. Often something about the puzzle suggests that an interdisciplinary approach is the most powerful way to unlock it.

A good example of interdisciplinary research framing in IB is Dunning's $(1980,1988)$ eclectic paradigm that focuses on three domains: firm-level assets and capabilities $(\mathrm{O})$, country-level economic and political systems (L) and firm-level transaction costs (I). By bringing together insights from these three domains, Dunning was able to develop a theory of international production superior to prior theories that focused on only one or two of these domains. Another example is Kogut's (1988) integration of three theoretical perspectives - transaction cost, strategic behavior and organizational learning - for why firms establish joint ventures. This analysis helped to clarify the conditions under which each perspective was most applicable to explaining joint venture decisions. Beyond the IB domain, Simon's (1945) seminal work on bounded rationality that combines insights from cognitive psychology and economics and North's (1990) integrative analysis of the co-evolution of institutions and national development (based on ideas from sociology, political science and economics) are both excellent illustrations of influential interdisciplinary research.

\section{OVERVIEW OF THE SPECIAL ISSUE}

With these considerations in mind, we worked with the editors of JIBS to develop a special issue on interdisciplinary research. We had two linked objectives. First, we wanted to showcase high-quality interdisciplinary research in $\mathrm{IB}$, in the hope that this would encourage more colleagues to work on explicitly bridging between disciplines in their own studies. Second, we wanted to provide an opportunity for the IB academic community, including journal editors, reviewers and authors, to learn from the special issue's experiences and collectively contribute to the development of an interdisciplinary research agenda for the field. In this editorial essay, we report on the main contributions of the special issue, and we offer some suggestions for how to move the interdisciplinary research agenda forward.

The call for papers for this issue attracted 60 submissions, which is consistent with the average submissions to other special issues. As is normally the case, we judged a number of submissions to be below the bar for further consideration, whether interdisciplinary or not. Others we judged as having no interdisciplinary content and these were moved to the regular IIBS review process. The remaining submissions were divided among the four action editors and sent out for review. Eight were given the opportunity to revise and resubmit, and five were ultimately accepted for publication.

A key issue that we faced was the enormous breadth of topics, disciplines and methodologies on display in these papers. None of us felt sufficiently expert in all the phenomena or methodologies to "master" the submissions, and we often drew on expert advice from colleagues in other fields to help us in our assessments. In reviewing the submissions, it was evident that authors held a wide variety of views about the meaning of interdisciplinary research, as did our reviewers. 
An important part of our role as special issue editors was to come to a shared view of what interdisciplinary research meant to us. We came to a view that both the individual disciplines, and the integration of ideas from those disciplines, had to be sufficiently well developed to provide a new theoretical argument, explanation or insight. On the basis of this point of view, we designed a supplemental set of manuscript evaluation criteria. We used these criteria to work with the prospective authors to develop their papers, while also satisfying the usual expectations of a JIBS publication.

Ahead, we provide a brief summary of the five accepted papers, highlighting the interdisciplinary elements of each and their respective contributions. We then build on these examples to offer some broader perspectives on the different ways interdisciplinary research can be conducted and the types of contributions it makes.

\section{PAPERS IN THE SPECIAL ISSUE}

\section{"Institutions sans Frontières: International Agree- ments and Foreign Investment," by Srividya Jandhyala and Robert Weiner}

This paper argues that the landscape influencing foreign direct investment goes beyond the home and host countries of multinational corporations (MNCs) to encompass international institutions institutions that themselves cross borders. Focusing on International Investment Agreements (IIAs), the authors combine insights from the international political economy, international law, theories of the MNC and finance literatures to build a theory of the multinational firm's political risk management. In a sharply drawn empirical test, the study shows how the presence or absence of IIAs influences the valuation of oil and gas assets, controlling for various aspects of the firm's multinationality and industry factors. Of special interdisciplinary interest is the cross-level finding that impact of IIAs on political risk (measured by valuation) depends on various characteristics of the multinational firm.

The key contribution of this paper is to bring cross-border institutions into the institutional framework that has generally been viewed as a national or sub-national phenomenon and to show explicitly how these interact with investor-firm characteristics to affect decisions and valuations. We expect this paper will be influential well beyond the specific domain of oil and gas, and will result in a much sharper delineation of institutional variables in future IB research of many kinds, where these are now often characterized by "black-boxing" the home or host country involved.

\section{"Firms' Corporate Social Responsibility Behavior: An Integration of Institutional and Profit Maxi- mization Approaches," by Susan Young and Mona Makhija}

By combining ideas from institutional theory in sociology and profit maximization theory in economics, this paper posits that firm motives for corporate social responsibility (CSR) involve both economic value seeking and normative social responsiveness, each drawing on a distinct disciplinary literature. Specifically, it argues that the influence of regulatory and normative institutions on how responsive firms are to the CSR agenda is not uniform across firms operating in the same institutional environment. Instead, this effect is contingent on those firm characteristics that shape the economic motivations for legitimacy-seeking behavior. Using data from the apparel industry based in 23 countries, the study confirms the general prediction that institutional influence on CSR responsiveness is contingent on a firm's levels of economic visibility (e.g., firm size) and economic vulnerability (e.g., resource dependence). The findings show that the less economically visible and vulnerable the firm, the weaker the influence of regulatory and normative institutions on its CSR responsiveness.

This paper makes a contribution to the special issue by demonstrating the promise of integrating ideas from two contrasting perspectives (sociology and economics) that have conflicting assumptions (social conformity vs free choice) about firm behavior. This was done by linking the economic effect of CSR on the firm to legitimacy-seeking behavior within the context of a socially embedded institutional environment. The result is a new and expanded understanding about why firms engage in CSR and the conditions that affect this engagement. Another contribution of this paper is its illustration of the utility of including explanatory factors from multiple levels in building theory about firm behavior.

\section{"Adaptation, Bridging and Firm Upgrading: How Non-Market Institutions and MNCs Facilitate Knowledge Recombination in Emerging Markets," by Rafael Corredoira and Gerald McDermott}

This paper integrates insights about firm learning from economic sociology and comparative capitalism. A standard argument in the comparative capitalism literature is that indigenous firms in developing 
countries often struggle to improve because of weak institutions and dysfunctional social capital. Using data on automotive parts suppliers in Argentina, the authors show how the interaction between global linkages (through MNC subsidiaries) and local innovation systems help indigenous firms to upgrade their capabilities. These findings support an alternative view in which local non-market institutions, such as industry associations and public research institutes, act as bridges between isolated industrial districts, and enable the transfer of applied knowledge. By combining this knowledge with advanced knowledge imported from outside, firms are to some extent able to overcome the weaknesses of their institutional context.

This paper does a good job of integrating ideas from two separate fields of research to arrive at novel insights. Studies in comparative capitalism have looked at the ways institutional linkages affect the transfer of knowledge within a country, while IB research has emphasized the role of the MNC in importing advanced knowledge from overseas. This paper essentially shows that these two different mechanisms of knowledge transfer are complementary, thus demonstrating the utility of an interdisciplinary approach in expanding our understanding about the effects of MNC linkages on local firms.

\section{"MNC Subsidiary Closures: What is the Value of Employees' Human Capital in New Jobs?" by Wolfgang Sofka, Miguel Torres Preto and Pedro de Faria}

This paper integrates ideas from labor economics on the displacement of employees following plant closures with IB research on the spillover effects of foreign direct investment in host country economies. Using a large data set of individuals in Portugal, the authors track the salaries paid to former MNC subsidiary employees in their subsequent jobs. They show that new employers pay higher wages when signals indicate that potential employees have valuable human capital (e.g., from having worked for a highly productive $\mathrm{MNC}$ ) and lower wages when signals indicate that potential employees have highly MNC-specific human capital (e.g., because of long tenure in the closed subsidiary).

This paper makes a novel empirical contribution, and it provides theoretical insight into a phenomenon that has not to our knowledge been studied in the IB or labor economics fields. It does this by developing a model that builds on and combines ideas from both fields. The resulting product is a new theoretical argument that more accurately explains and predicts the market value of displaced employees as a result of plant closures.

\section{"Consumer Responses to Sexual Advertising: The Intersection of Modernization, Evolution and International Marketing," by Wendy Wan, Chung- Leung Luk and Cheris Chow}

This paper draws on theories from evolutionary psychology and sociology to explain consumer responses to nudity in advertising across levels of modernization. The authors conducted a quasiexperiment in which the independent variable (gender in the stimulus material) was manipulated across different levels of modernization, specifically a range of cities in China with very different levels of economic development. A variety of other sociocultural factors were controlled for. This crisp empirical study sheds light on the complex topic of variation in consumer response to the frequent use of sexual content in advertising across national (cultural) contexts. It does so by first examining the phenomenon in terms of multiple theoretical perspectives on universals of human behavior, and then seeking to understand the influence of societal context. In addition it uses a cross-sectional study that is analogous to the longitudinal phenomenon of interest.

The research applies an interdisciplinary theoretical lens to an IB question. The fact that evolutionary psychology itself is an amalgam of evolution/ biology, physiology, psychology, ecology and sociology raises an interesting point about where in the theoretical development integration occurs. Somewhat similar predictions about consumer responses might be derived from strategic pluralism theory or social structural theory, both of which are subsets of the overall theoretical perspective within evolutionary psychology. However, what is very clear is that these new insights are unlikely to have been achieved from the standpoint of a single discipline. This article is interesting both for its approach and its findings.

\section{INSIGHTS GAINED FROM THE SPECIAL ISSUE}

The five papers in this special issue address very different topics, and each one makes its own distinctive interdisciplinary contribution to our understanding of IB issues. They share several important characteristics. First, and most obviously, each study brings together ideas from at least two separate bodies of literature and offers new insights that could not have been arrived at using one body of literature on its own. For example, by applying ideas 
from evolutionary psychology and sociology, Wan et al. answer some important research questions in international marketing concerning consumer responses to sexual advertising across different levels of economic development.

Second, all the papers span multiple levels of analysis. For example, Corredoira and McDermott use firm-level data to shed light on a country-level phenomenon, while Sofka et al. use individual-level data to make sense of firm-level issues. Again, this is not necessarily a surprising common feature. Most academic disciplines gravitate toward a particular level of analysis - the individual in psychology, the organization in sociology, the nation-state in political science - so to the extent that one wants to study issues that span levels of analysis, an interdisciplinary approach is likely to be necessary.

Third, the papers all develop a new integrative theoretical argument that provides a more complete perspective on the phenomenon under investigation. Jandhyala and Weiner and Young and Makhija, for example, do this by investigating the interaction effects between factors identified by different disciplines as important explanatory variables. Corredoira and McDermott and Sofka et al. put forward arguments with improved explanatory power by examining the additive effects of factors based on different perspectives. Through the lens of strategic pluralism theory, Wan et al. help to reconcile discrepancies in several evolutionary theories.

There are important differences as well, not just in the range of phenomena, methodologies and disciplines involved, but also in terms of the motivation and type of contributions they make. Specifically, we observe four approaches to interdisciplinary inquiry across the five papers.

\section{Addressing a New Phenomenon}

An interdisciplinary approach can open our eyes to objects of study that had previously been ignored. For example, Jandhyala and Weiner put the spotlight on IIAs, which have been acknowledged in the academic literature but poorly understood. By showing how these agreements influenced the valuations of assets in the oil and gas sector, they were able to develop a theoretically compelling argument for how IIAs play an important role in our understanding of globalization.

\section{Asking a Fresh Question}

Sometimes the value of bringing in ideas from a separate discipline is that it stimulates researchers to ask questions that they might not have thought about before. For example, Sofka et al. address the broad question of how MNCs influence productivity enhancements in host countries by focusing specifically on the employment opportunities for displaced workers in Portuguese subsidiary companies. This fresh angle on an old phenomenon would likely not have transpired without inspiration from the field of labor economics.

\section{Finding a Better Answer}

By bringing together ideas from two or more disciplines, it is often possible to come up with insights that would not have emerged from one discipline alone. For example, Corredoira and McDermott show that process improvements in automotive suppliers were highest in those with ties to both local institutions and MNC subsidiaries, while Wan et al. examine the interaction effect of gender and level of economic development on response to nudity. As one useful rule of thumb, showing that constructs drawn from different disciplines interact in a meaningful way to improve explanatory prediction is evidence that an interdisciplinary approach has been successful.

\section{Contributing to a Base Discipline}

By asking better questions and/or finding better answers, it is also sometimes possible to develop new theoretical ideas that can be taken back to one or both base disciplines. For example, Young and Makhija's findings that firms' involvement in CSR is a joint outcome of interactive influences from societal-level forces and firm-level economic motivations challenge the basic assumptions of social conformity in sociology-based institutional theory and free choice in economics-based profit maximization theory about firm behavior. This, in turn, will help both disciplines to further refine and develop their respective theories.

\section{CONCLUSION}

The primary objective of this special issue is to showcase high-quality interdisciplinary research in the IB field, with a view to inspire and educate others on how such research should be conducted. Our purpose in this editorial essay has been to discuss some of the insights we gained during the review process, and to highlight a range of different approaches that fit under the "interdisciplinary" umbrella. By clarifying the challenges and opportunities inherent in this type of inquiry, we hope to encourage more members of the IB community to 
consider an interdisciplinary approach in their own research.

As noted earlier, we do not view interdisciplinarity as an end in itself. Rather, it is an approach to research that is appropriate for tackling certain types of research problems, typically those spanning multiple levels of analysis, or those that are seeking to come to grips with poorly or partially understood

\section{REFERENCES}

Birkinshaw, J., Brannen, M. Y., \& Tung, R. 2011. From a distance and generalizable to up close and grounded: Reclaiming a place for qualitative methods in international business research. Journal of International Business Studies, 42(5): 573-581.

Buckley, P. J., \& Lessard, D. R. 2005. Regaining the edge for international business research. Journal of International Business Studies, 36(6): 595-599.

Cantwell, J., \& Brannen, M. Y. 2011. Positioning JIBS as an interdisciplinary journal. Journal of International Business Studies, 42(1): 1-9

Cheng, J. L. C., Henisz, W., Roth, K., \& Swaminathan, A. 2009 Advancing interdisciplinary research in the field of international business: Prospects, issues, and challenges. Journal of International Business Studies, 40(7): 1070-1074.

Cheng, J. L. C., Guo, W., \& Skousen, B. 2011. Advancing new theory development in the field of international management: Contributing factors, investigative approach, and proposed topics. Management International Review, 51(6): 787-802.

Daniels, J. 1991. Relevance in international business research: A need for more linkages. Journal of International Business Studies, 22(2): 177-186.

Dunning, J. H. 1980. Toward an eclectic theory of international production: Some empirical tests. Journal of International Business Studies, 11(1): 9-31.

Dunning, J. H. 1988. The theory of international production. International Trade Journal, 3(1): 21-66.

Dunning, J. H. 1989. The study of international business: A plea for a more interdisciplinary approach. Journal of International Business Studies, 20(3): 411-436.

Kogut, B. 1988. Joint ventures: Theoretical and empirical perspectives. Strategic Management Journal, 9(4): 319-332.

North, D. 1990. Institutions, institutional change and economic performance. New York: Cambridge University Press.

Rugman, A. M., Verbeke, A., \& Nguyen, Q. T. K. 2011. Fifty years of international business theory and beyond. Management International Review, 51(6): 755-786.

Simon, H. A. 1945. Administrative behavior. New York: Free Press.

\section{ABOUT THE AUTHORS}

Julian Birkinshaw (PhD, Richard Ivey School of Business) is Professor of Strategy and Entrepreneurship at the London Business School. He is a Fellow of the British Academy and the Academy of International Business. His main area of expertise is in the strategy and organization of large multinational corporations, and on such specific issues as subsidiary-headquarters relationships, corporate entrepreneurship, innovation, phenomena. But when conducted appropriately and with skill, it is an approach to research that can generate great insights and be highly influential.

\section{ACKNOWLEDGEMENTS}

We thank John Cantwell and three anonymous reviewers for their very helpful and constructive comments on an earlier draft of the editorial essay.

the changing role of the corporate headquarters, organization design and knowledge management.

Joseph LC Cheng (PhD, University of Michigan) is Professor of Management and holds the Michael J Crouch Chair in Innovation at the Australian School of Business, University of New South Wales. Prior to his current appointment, he was Professor of International Business and Director of The CIC Center for Advanced Study in International Competitiveness at the University of Illinois at Urbana-Champaign. His current research examines the changing pattern of foreign R\&D investment in the Asia-Pacific and its effects on innovation and entrepreneurship across the region, particularly among the JACKS countries (Japan, Australia, China, Korea and Singapore).

Donald R Lessard (PhD, Stanford University) is the Epoch Foundation Professor of International Management Emeritus at the MIT Sloan School of Management. His research interests are on global strategic management, project management and risk management with an emphasis on the energy sector. He has published extensively on these topics in academic and professional journals. A leader in international management education, he is a past President of the Academy of International Business and Dean of the Fellows of the Academy.

David C Thomas (PhD, University of South Carolina) is Professor of International Business at the Australian School of Business, University of New South Wales. He is the author of ten books including the best-selling Cultural Intelligence: Living and Working Globally (2009), and Cross-Cultural Management Essential Concepts (2008), the winner of the R Wayne Pace Human Resource Development book of the year award. 